\title{
Aluminium in the blood and urine of industrially exposed workers
}

\author{
B SJÖGREN, I LUNDBERG, AND V LIDUMS \\ From the Section of Occupational Medicine, Research Department, National Board of Occupational Safety \\ and Health, S-171 84 Solna, Sweden
}

ABSTRACT Blood and urine aluminium concentrations were studied in industrially exposed workers using electrothermal atomic absorption spectrometry. Welders and workers making aluminium powder and aluminium sulphate had higher concentrations in blood and urine than non-exposed referents. Workers in the electrolytic production of aluminium had higher urine but not blood concentrations than the referents. Thus aluminium was found to be absorbed by all industrially exposed workers. Blood concentrations were lower than those presumably associated with aluminium induced encephalopathy in patients receiving dialysis.

Aluminium compounds are ubiquitous in nature. The earth's crust contains about $8 \%$ aluminium and food contains varying amounts. Concentrations are higher in meat, grain, and vegetables than in fish and milk. ${ }^{1}$

Aluminium is accumulated by dialysis patients because of their renal failure and a relationship has been established between the concentration of aluminium in the water used for dialysis and the development of dialysis encephalopathy. ${ }^{2}$ Increased concentrations of aluminium in the brain have also been found in patients suffering from Alzheimer's disease. $^{3}$ One case of dementia and pulmonary fibrosis in an aluminium powder production worker was described in $1962^{4}$ and, in addition, some aluminium salts are known to be neurotoxic in animals. $^{3}$

The purpose of the present study was to investigate the concentrations of aluminium in the blood and urine of industrially exposed workers and nonexposed referents to determine whether aluminium is absorbed from the air exposure in certain working environments. One earlier study has shown that workers exposed to an aluminium containing mineral (corundum) have raised aluminium concentrations in the urine. ${ }^{5}$ Also aluminium containing antacids given by mouth are absorbed from the gastrointestinal tract to some extent. ${ }^{6}$

Received 17 May 1982

Accepted 23 July 1982

\section{Material}

Workers exposed to aluminium in four different industrial processes took part in the study: electrolytic production of aluminium (A), production of aluminium powder (B), production of aluminium sulphate (C), and aluminium welding (D). The factories were located in different parts of Sweden and unexposed referents were selected from the different areas. For comparison, a group of patients receiving dialysis with renal failure also participated (E). The study was performed in 1980.

The exposed group consisted of 81 men and 12 women (mean age 40) (SD 13 years). The number of smokers and non-smokers was equal. The referent group consisted of 49 men and 29 women, (mean age 42 ) (SD 12 years); $40 \%$ were smokers.

$A$-Several aluminium compounds are used in the elctrolytic production of aluminium: aluminium oxide $\left(\mathrm{A} 1_{2} \mathrm{O}_{3}\right)$, cryolite $\left(\mathrm{Na}_{3} \mathrm{~A}_{1} \mathrm{~F}_{6}\right)$, and aluminium fluoride $\left(\mathrm{A}_{1} \mathrm{~F}_{3}\right)$. The exposure of the group varies but total mean particle values during the past years have been $1.1-4.9 \mathrm{mg} / \mathrm{m}^{3}$ air. The mean exposure time for the group was 3.8 years (range 0.2-27).

$B$-When manufacturing aluminium powder and flakes, melted aluminium is "atomised" by means of compressed air to form more or less spherical particles, $150 \mu \mathrm{m}$ in diameter. The powder is ball-milled with white spirit. After drying, the powder consists of flakes $10-50 \mu \mathrm{m}$ long and $0.6 \mu \mathrm{m}$ thick, which are used for the production of explosives and light concrete. Mean exposure time of these workers was $10 \cdot 2$ years (range $0 \cdot 5-30$ ). 
$C$-Aluminium sulphate $\left(\mathrm{Al}_{2}\left(\mathrm{SO}_{4}\right)_{3}\right)$ is made by treating aluminium oxide with sulphuric acid. The airborne concentration has varied from $0 \cdot 1$ to 9.3 $\mathrm{mg} / \mathrm{m}^{3}$, and might have been higher during short periods. Mean exposure time of the group was $\mathbf{7 . 4}$ years (range $0 \cdot 2-21$ ).

$D$-Aluminium is welded by different gasshielded techniques. The generated particles are generally less than $1 \mu \mathrm{m}$ and thus respirable. Total particle exposure has varied between 0.5 and 37.2 $\mathrm{mg} / \mathrm{m}^{3}$ during 1975 and 1976 . In later years the local exhaust ventilation has been improved and exposure was probably lower at the time of this study. The mean exposure time of the group was 10.7 years (range 0.3-32).

$E$-The group of dialysis patients consisted of eight men and 11 women (mean age 51) (range 27-66). They exhibited no clinical signs of encephalopathy. Mean time for dialysis was 2.8 years (range 0.4-8).

Patients with renal insufficiency often have high concentrations of serum phosphate. When ingested, soluble aluminium compounds will form nonsoluble complexes with phosphates in the gastrointestinal tract and decrease the serum phosphate concentrations. All patients receiving dialysis ingested such aluminium containing drugs. The water used for dialysis is purified by reverse osmosis, which decreases the aluminium concentrations from 31 $\mu \mathrm{g} / \mathrm{l}$ to under $3 \mu \mathrm{g} / \mathrm{l}$.

Determinations of total particle exposure were performed by the local occupational safety engineer (plants $\mathrm{A}$ and $\mathrm{C}$ ) and by representatives from the research department at the National Board of Occupational Safety and Health (plant D).

\section{Methods}

\section{SAMPLING}

Blood was taken into polystyrene test tubes and urine into $500 \mathrm{ml}$ polyethylene bottles. Test tubes, bottles, lids, and pipette-tips were carefully cleaned. They were first soaked in 5\% RBS-25 solution for at least five hours and then in 1\% EDTA-solution overnight. The next morning they were carefully rinsed in ion-free water. Any type of drying was excluded. The test tubes were prepared with $30 \mu \mathrm{l}$ heparin, $10000 \mathrm{IU} / \mathrm{ml}$ (KABI AB).

Blood and urine samples were taken at the end of a working day after some days of exposure. All the exposed subjects had a shower and changed into their ordinary clothes before sampling. Blood was collected from a vein through a Wasserman needle, some blood being washed through the needle before sampling. Urine was voided after careful personal instructions to avoid dust contamination.
Blood samples were stored at $-20^{\circ} \mathrm{C}$. The urine samples were divided into two portions, a small amount being preserved for creatinine estimation. To the remainder, $9 \mathrm{M}$ sulphuric acid (Mercks, Suprapur $1+1$ ) was added in a volume equal to $1.5 \%$ of the urine sample. The samples were stored at $-20^{\circ} \mathrm{C}$ until analysis.

\section{DETERMINATION OF ALUMINIUM}

A Perkin-Elmer Model 403 atomic absorption spectrophotometer, equipped with a Deuterium background corrector, HGA-74 graphite furnace, model 056 recorder and Intensitron aluminium hollow cathode lamp was used. Measurements were made at $309.3 \mathrm{~nm}$, the slit-width was $0.7 \mathrm{~nm}$, scale expansion was set at $0.25 \mathrm{Abs}$ or $0.50 \mathrm{Abs}$, and the purge gas was argon.

Several matrix modifiers are recommended for the analysis, ${ }^{7-9}$ but when tried they were found to contain considerable amounts of aluminium. On this account only ammonium hydroxide, purified by isothermal distillation, ${ }^{10}$ was used. It was added to modify the chloride influence and to prevent build up of residues in the graphite tube.

Blood was diluted $1+4$ and urine $1+1$ with water and ammonium hydroxide to give about $3 \mathrm{M}$ concentration of ammonia in the resulting solutions. Sample aliquots of $25 \mu \mathrm{l}$ were introduced with a Finnpipette, the tips being rinsed with water and finally three times with the sample.

The heating programme was: drying by gradual increase from $80^{\circ} \mathrm{C}$ to $400^{\circ} \mathrm{C}$ in 2.5 minutes, ashing, ramp 8 to $1250^{\circ} \mathrm{C}$ for blood and ramp 8 to $1480^{\circ} \mathrm{C}$ for urine; atomising, $2700^{\circ} \mathrm{C}$ for 10 seconds, gas stop. The method of standard additions was used for calibration.

The detection limit for aluminium in blood was 5 $\mu \mathrm{g} / \mathrm{l}$ and for urine $3 \mu \mathrm{g} / \mathrm{l}$. At a concentration of 50 $\mu \mathrm{g} / \mathrm{l}$, the coefficient of variation for nine blood analyses was $7.9 \%$ and the mean recovery of added amounts of aluminium was $99 \%$. The coefficient of variation for nine urine analyses at $40 \mu \mathrm{g} / \mathrm{l}$ was $6.2 \%$. The mean recovery of added amounts was $102 \%$.

\section{DETERMINATION OF CREATININE}

Creatinine was determined by a colorimetric method on a reaction rate analyzer LKB $8600 .{ }^{11}$

\section{STATISTICAL METHODS}

Group differences of aluminium concentrations were analysed with Wilcoxon's ranking test. Linear relationships were tested with Student's $t$ test. In all calculations two-tailed tests were used. Differences were considered statistically significant when $p$ was less than $0 \cdot 05$. 


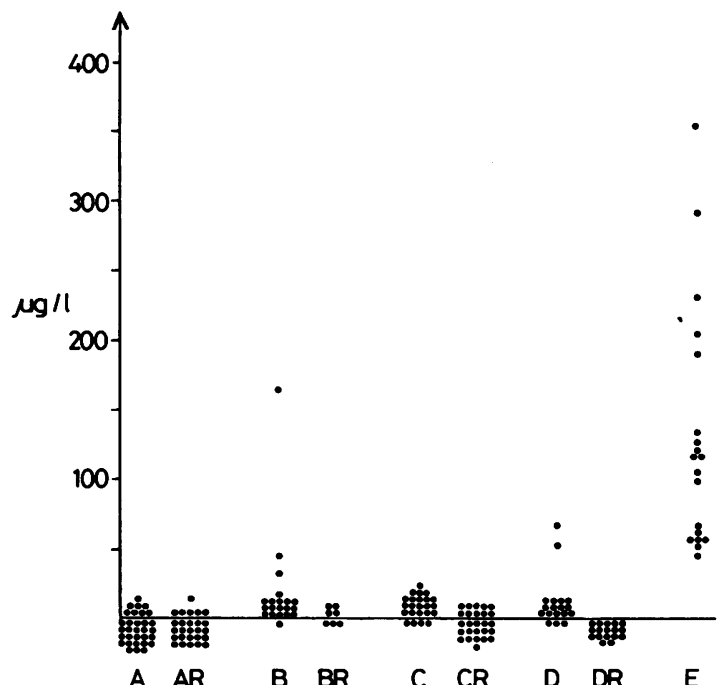

Fig 1 Blood aluminium concentrations. A Exposed in electrolytic production of aluminium. B Exposed in production of aluminium powder. $C$ Exposed in production of aluminium sulphate. D Aluminium welders. E Patients receiving dialysis. $R$ Referents from same area as respective exposed group. Each point represents concentration for one person.

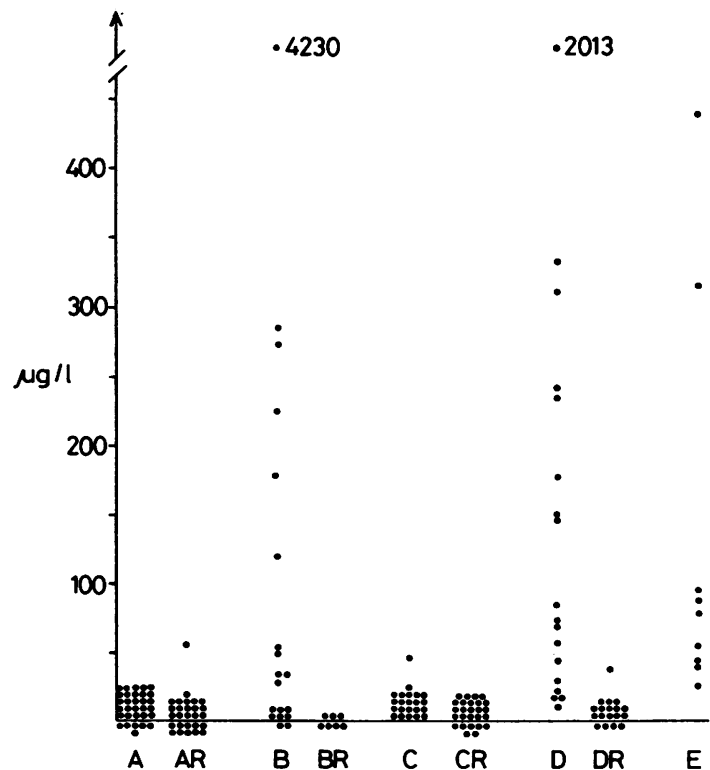

Fig 2 Urine aluminium concentrations. $A$ Exposed in electrolytic production of aluminium. $B$ Exposed in production of aluminium powder. $C$ Exposed in production of aluminium sulphate. D Aluminium welders. E Patients receiving dialysis. $R$ Referents from same area as respective exposed group. Each point represents concentration for one person.
Results

Patients receiving dialysis had the highest blood concentration of aluminium (fig 1). All the industrially exposed groups, except the workers in the electrolytic production of aluminium, had significantly higher blood concentrations than their respective referents. All exposed groups had significantly higher urine concentrations of aluminium than their respective referents (fig 2). Patients receiving dialysis, welders, and workers producing aluminium powder had the highest concentrations in urine.

In the exposed group as a whole a linear relationship was found between blood and urine concentrations of aluminium: $y=24.3-226(r=0.94, n=$ 58 ), where $x$ is the blood concentration and $y$ is the urine aluminium concentration. All concentration values are given in $\mu \mathrm{g} / 1$. The standard error of estimate (SEE) was substantial, $206 \mu \mathrm{g} / 1$. A linear relationship was also found when urinary concentrations were adjusted to creatinine: $y=16 \cdot 0 x-133(r=$ $0.97, n=49$, SEE $=104)$, where $x$ is the blood concentration and $y$ is the urine aluminium concentration expressed as $\mu \mathrm{g} / \mathrm{g}$ creatinine.

The two people having the highest urinary concentrations of aluminium also had the highest blood concentrations. If they are excluded from regression, the equation has the form: $y=5 \cdot 23 x-3 \cdot 16$ $(r=0 \cdot 50, n=56, S E E=81 \cdot 0)$. The corresponding relationship when urine concentrations were corrected to creatinine was: $\mathrm{y}=6.28 \mathrm{x}-21.6(\mathrm{r}=$ $0 \cdot 52, \mathrm{n}=47$, SEE $=74 \cdot 7$ ).

Whole blood and plasma aluminium concentrations were both determined in four patients receiving dialysis who had blood concentrations above 100 $\mu \mathrm{g} / 1$. The mean plasma concentration was $8 \%$ lower than the concentration in whole blood.

The duration of the exposure time of the welders showed a linear relationship with urinary aluminium concentrations when these were adjusted to creatinine: $y=24 \cdot 3 x-56 \cdot 4(r=0.64, n=14)$, where $\mathrm{x}$ is exposure time in years and $\mathrm{y}$ is aluminium concentration expressed as $\mu \mathrm{g} / \mathrm{g}$ creatinine. Exposure time and urine concentration did not show a significant linear relationship in the other exposed groups. Urine aluminium concentrations were not associated with gender, age, or smoking habits in any of the groups studied.

The median urine concentration of the referents was $4 \mu \mathrm{g} / 1$. Four referents, who took some kind of aluminium containing drug, all had concentrations above $4 \mu \mathrm{g} / 1 \quad(5-15 \mu \mathrm{g} / 1)$. Eight industrially exposed workers ingested aluminium containing drugs but none had concentrations that deviated in any remarkable way from their respective group. 
Concentrations of aluminium in the drinking water from the four industrial areas varied between three and $10 \mu \mathrm{g} / 1$.

\section{Discussion}

The concentrations of aluminium in the blood of the industrially unexposed subjects were close to the lowest plasma or serum concentrations reported earlier. ${ }^{72}$ Some other investigations have found much higher concentrations of aluminium in non-exposed subjects. Pretreatment of samples and the use of additives were avoided so far as possible owing to the risks of contamination at such steps in the analysis. The required sensitivity was established by a minimum of dilution and a well adjusted drying and ashing programme for the graphic furnace.

Dogs given aluminium chloride intravenously excreted one third of the dose within two hours, indicating an initially fast phase of renal excretion. ${ }^{13}$ We found high urinary concentrations in dialysis patients with renal insufficiency and in some industrially exposed groups. Nevertheless, blood concentrations were much higher in the patients receiving dialysis. These data suggest that the kidney plays an important part in the excretion of aluminium.

The study showed a linear relationship between years of exposure and urinary aluminium concentration in welders. An earlier study observed an increasing concentration of aluminium in the lungs with increasing age among industrially non-exposed subjects. ${ }^{14}$ These facts indicate that a fraction of aluminium may accumulate in the body.

There was a linear relationship between blood and urine aluminium concentrations, but this was largely due to the subjects with extreme values.

Earlier studies have suggested that dialysis encephalopathy may occur when the serum aluminium concentration exceeds 250-300 $\mu \mathrm{g} /$ 1. ${ }^{15-17}$ Patients receiving dialysis with high serum aluminium concentrations (mean $75 \mu \mathrm{g} / 1$ ) did not differ from patients with low serum concentrations (mean $17 \mu \mathrm{g} / 1$ ) in psychometric tests. ${ }^{18}$ Exposure to aluminium powder during its production has been tentatively associated with one case of brain damage, ${ }^{4}$ but psychometric tests have never been performed on industrally exposed groups and it seems unlikely that toxic encephalopathy would be associated with the blood aluminium concentrations found in this study. Future studies will, however, be needed to exclude aluminium as a cause of psychological disturbances in workers exposed for many years.
This study has been supported by the Swedish Work Environment Fund, grant no 79/309.

We thank Mr Kent Wrangskogh for his determination of creatinine.

Requests for reprints to Bengt Sjögren.

\section{References}

${ }^{1}$ Koivistoinen P. Mineral element composition of Finnish foods. Acta Agriculture Scandinavica 1980; suppl 22.

${ }^{2}$ Alfrey AC, Hegg A, Craswell P. Metabolism and toxicity of aluminium in renal failure. Am J Clin Nutr 1980;33:1509-16.

${ }^{3}$ Crapper McLachlan DR, DeBoni U. Aluminium in human brain disease-an overview. Neurotoxicology 1980;1:3-16.

4 McLaughlin AIG, Kazantzis G, King E, Teare D, Porter RJ, Owen R. Pulmonary fibrosis and encephalopathy associated with the inhalation of aluminium dust. $\mathrm{Br} J$ Ind $\mathrm{Med}$ 1962;19:253-63.

5 Valentin H, Preusser P, Schaller K-H. Die Analyse von Aluminium im Serum und Urin zur Uberwachung exponierter Personen. Int Arch Occup Environ Health 1976;38:1-17.

' Kaehny WD, Hegg AP, Alfrey AC. Gastrointestinal absorption of aluminium from aluminium-containing antacids. $N$ Engl $J$ Med 1977;296:1389-90.

${ }^{7}$ Alderman FR, Gitelman HJ. Improved electrothermal determination of aluminium in serum by atomic absorption spectroscopy. Clin Chem 1980;26:258-60.

- Gorsky JE, Dietz AA. Determination of aluminium in biological samples by atomic absorption spectrophotometry with a graphite furnace. Clin Chem 1978;24:1485-90.

- Pegon Y. Dosage de l'aluminium dans les liquides biologiques par absorption atomique sans flamme. Anal Chim Acta 1978;101:385-91.

${ }^{10}$ Veillon C, Reamer DC. Preparation of high-purity volatile acids and bases by isothermal distillation. Anal Chem 1981;53:549-50.

"Method for creatinine determination by LKB 8600 reaction rate analyzer, Boehringer Mannheim GMBH. Diagnostica 1975.

12 Versieck J, Cornelis R. Normal levels of trace elements in human blood, plasma, or serum. Anal Chim Acta 1980;116:217-54.

${ }^{13}$ Kovalchik MT, Kaehny WD, Hegg AP, Jackson JT, Alfrey AC. Aluminium kinetics during haemodialysis. J Lab Clin Med 1978;92:712-20.

14 Alfrey AC. Aluminium metabolism in uremia. Neurotoxicology 1980;1:43-53.

is Elliott HL, Dryburgh F, Fell GS, Sabet S, MacDougall AI. Aluminium toxicity during regular haemodialysis. $\mathrm{Br} \mathrm{Med} J$ 1978;i:1101-3.

${ }^{16}$ Masselot JP, Adhemar JP, Jaudon MC, Kleinknecht D, Galli A. Reversible dialysis encephalopathy: role for aluminiumcontaining gels. Lancet 1978;ii:1386-7.

${ }^{17}$ Poisson M, Mashaly R, Lebkiri B. Dialysis encephalopathy, recovery after interruption of aluminium intake. $\mathrm{Br} \mathrm{Med} J$ 1978; ii:1610-1.

18 Rosati G, De Bastiani P, Gilli P, Paolino E. Oral aluminium and neuropsychological functioning, a study of dialysis patients receiving aluminium hydroxide gels. J Neurol 1980;223:2517. 